\title{
UIT DIE WORDINGSGESKIEDENIS VAN DIE HERVORMDE KERK.
}

Die geskiedenis van ons Kerk gaan, saam met diê van ons land en volk, tot in die dae van Jan van Riebeeck terug. In 1665 het die bewoners van die klein nedersetting aan Tafelbaai hul eerste leraar Johan van Arkel - verwelkom ') en van daardie jaar af het die leraars die Woord oor die lengte en breedte van ons land uitgedra. Twee eeue na die aankoms van Jan van Riebeeck aan die Kaap het Ds. D. van der Hoff in die Oorvaalse met sy herderlike werk begin. Dit was 'n nuwe mylpaal in die geskiedenis van ons Kerk.

Byna drie eeue het leraars die Woord in ons land verkondig. Watter groot voorreg het hulle besit om in volle vryheid in Godshuise, op huisbesoeke en by plegtige samekomste in die opelug die Evangelie aan almal te kan bring. Vryheid van geloof en geloofsoortuiging en vryheid van prediking is van die pragtigste perrels in die geskiedenis van Suid-Afrika. Vandag beskou ons dit as vanselfsprekend, as n tradisie, as onderdele van die onvervreemdbare regte waaroor elke mens beskik, as 'n deel van ons lewe. Maar nie orals is en word selfs vandag in ons hooggeprese twintigste eeu, hierdie regte in al die lande van die wêreld erken nie. Selfs in ons eeu behoort geloofsvervolgings. nog nie tot die verlede nie, nog nie orals kan die gelowige God op sy wyse aanbid en eer nie. Dat in ons land daardie treurige omstandighede van die begin van ons geskiedenis af nooit bestaan het nie, kan toegeskrywe word aan die geweldige worsteling van die lidmate van ons Moederkerk - die Nederlands Hervormde Kerk — om daardie reg te verkry. Wanneer Jan van Riebeeck aan die Kaap verskyn, is daardie stryd reeds iets van die verlede, die oorwinning is reeds behaal en Suid-Afrika was die eerste land wat die vrugte van daardie oorwinning gepluk het.

Gaan ons terug in die geskiedenis van ons Moederkerk in die Nederlande, dan kan ons leer dat die regte wat ons vandag as vanselfsprekend beskou eers na 'n langdurige, afmattende en uitputtende stryd van ' $n$ aantal onversaagde gelowiges verkry is en dat die Hervormde Kerk in die Nederlande in bloed en trane gebore is, gebore -op vreemde grond omdat die heersers van die Nederlande van daardie dae hulle met hand en tand teen die stigting van ons Moederkerk verset het.

Gewoonlik word die optrede van Luther in die jaar 1517 as die begin van die Kerkhervorming beskou. Sonder om die daad van hierdie Hervormer te wil verkleineer is dit duidelik dat sy optrede die resultaat van 'n geestelike gistingsproses was, 'n proses wat reeds

1) S. P. Engelbrecht: Geskiedenis van die Nederduitsch Hervormde Kerk van Afrika, bls. 2. 
jarelank aan die gang was. In die Nederlande het geleerdes soos Wessel Gansfort, Rudolf Agricola en die beroemde Desiderius Erasmus reeds voordat Luther met die Roomse Kerk gebreek het, in woord en geskrif hul ontevredenheid met daardie Kerk te kenne gegee. Waar hulle leiers was en daardeur ' $n$ groot naam in die geskiedenis verwerf het, is daar, soos orals in.die geskiedenis van die wêreldgebeure, 'n groot aantal ongenoemdes en onbekendes. Waar die geleerdes in staat was om gedagtes te formuleer en in 'n vaste vorm te giet, daar het hulle op hul wyse gevoel dat daar verandering en verbetering moet kom. Die Roomse Kerk kon hulle nie meer bevredig nie en hierdie onbevredigdes het na nuwe paaie begin soek, paaie wat na Waarheid sou lei, paaie waarlangs die ware Evangelie tot hulle sou kom.

Eers het hulle in stilte begin soek om vervolgens openlik met hul menings voor die dag te kom. Wat Luther in 1517 in Wittenberg doen nl. openlik met die Katolieke Kerk breek, het in die Nederlande die Sakramentiste en die Anabaptiste gedoen. Hulle het hul gehoorsaamheid aan daardie Kerk opgesê. Die optrede van Luther in Duitsland en die twee groepe in die Nederlande staan los van mekaar. Slegs in ' $n$ paar stede in die Nederlande, o.a. in Antwerpen het die Lutheranisme posgevat en selfs daar was die aantal Lutherane gering in aantal en verskyn hulle eers later. ${ }^{2}$ ) Die Nederlandse bewegings is selfstandig en dit is die beste bewys dat Wes-Europa ryp was vir ' $n$ groot geestelike omwenteling wat op verskillende plekke en in verskillende vorms tot uiting gekom het.

Van die begin af het die aanhangers van hierdie stromings op 'n tweeledige teenstand gestuit. Allereers van die kant van die wêreldlike owerheid, tweedens van die kant van die Roomse Kerk. Al hierdie owerhede en gesagdraers het eendragtig saamgewerk om die opkomende vloedgolf te beteuel en - te vernietig.

In die jare 1515-55 het die Nederlande onder die gesag van Karel V gestaan. Hy was tewens regeerder oor die Duits-Oostenrykse lande en koning van Spanje. Allereers was hy 'n getroue aanhanger van die Roomse Kerk en verder het hy - soos die meeste van sy tydgenote - daarin geglo dat vryheid van geloof en geloofsoortuiging slegs in verbeelding bestaan. Soek na Waarheid was afdwaal van die enigste erkende Kerk in sy ryk en dit moes en sou gestraf word. Vanselfsprekend kon hy op heelhartige ondersteuning van die gesagdraers van die Roomse Kerk reken. Ook om staatkundige redes was Karel V teen verdeeldheid op kerklike gebied. Skeuring van die Kerk sou maklik tot verbrokkeling van sy uitgestrekte ryk kan lei en dit moes tot elke prys vermy word. Al hierdie faktore het 'n donker toekoms vir die ",afgedwaaldes" beteken.

2) J. Romein: De lage landen bij de zee, bls. 198. 
Tog was dit nog nie alles nie. Behalwe 'n godsdienstige hervorming wou die Anabaptiste ook 'n nuwe maatskaplike orde invoer. Hulle droom van 'n samelewing waarin arm en ryk nie meer sou bestaan nie, waarin gemeenskaplike besit privaatbesit sou vervang. Hierdie kenmerk het die genadeslag vir die beweging beteken en kort na 1530 is die meeste aanhangers uitgeroei. ${ }^{3}$ ) Reeds kort na 1520 het die eerste geloofsmartelaars op die brandstapel hul lewe verloor. Steeds strenger en hardvogtiger het die owerhede begin optree. Die bewegings is langsaam maar seker van hul leiers berowe en nadat, kort na 1530, die meeste Anabaptiste uitgeroei was, het die regering in 1535 die volgende wet uitgevaardig. Elke Anabaptis wat in sy geloof volhard, persone bekeer of doop of as voorganger optree, wag die brandstapel. Elkeen wat 'n Anabaptis geherberg het of elke Anabaptis wat berou toon, sal met die swaard of deur verdrinking gestraf word. Maar so skrywe Van Schelven op 'n treffende wyse - ofskoon die beweging van sy leiers berowe was - het die boom wat by die grond afgekap was, weer begin oplewe. ${ }^{4}$ ) Van die kant van die Anabaptiste het hierdie oplewing nie.gekom nie. Hulle het onder leiding van 'n voormalige Roomse geestelike (Menno Simons) 'n vreedsame sekte geword wat die swaard afgelê het en onder die naam Doopsgesindes vandag nog in Nederland aangetref word..$^{5}$ )

Tog het die Nederlande in 'n toestand van geestelike beroering gebly en moes die owerhede konstateer dat, ondanks swaar strawwe en onmenslik wrede wetgewing, die afvalligheid van die bevolking van die Roomse Kerk steeds toeneem. In hierdie tyd het nuwe lewenssappe langsaam maar seker hul weg na die Nederlande gevind, nuwe kragbronne waaruit die verdruktes moed en wilskrag geput het. Hierdie kragbron was die leer van Calvyn. Vanuit Genève het die Calvinisme na die Nederlande uitgestraal, predikers het die nuwe leer onder die Nederlanders begin versprei en daardeur het 'n aantal rotsvaste, geharnaste stryders hul verskyning gemaak. Nog altyd het die wette strenger geword, maar die afgryslikste bedreigings was nie in staat om die wetgewers te laat seëvier nie. Wel het 'n groot aantal Nederlanders hul geboorteland verlaat om op veiliger plekke hul geloofsoortuiging uit te lewe, maar dit het geen oorwinning vir hul vervolgers beteken nie. In hierdie opsig kan ons 'n parallel met Lodewyk XIV en sy stryd teen die Hugenote trek. ${ }^{6}$ ) Ook daar ontmoet ons 'n aantal vasberade Calviniste wat alles in die steek gelaat het om hul geloof te kan behou en vryelik te kan uitlewe.

3) Oor die bedrywighede te Munster en Amsterdam in 1534 en 1535 o.a. J. Romein. bls. 199 e.v. 'n Letterkundige beskrywing van die samelewing in Munster gee P. H. van Moerkerken: Het Nieuwe Jeruzalem.

4) A. A. van Schelven: De Nederduitsche Vluchtelingenkerken der XVle eeuw, bls. 5 .

5) o.a. P. Geyl: Geschiedenis van de Nederlandsche Stam, deel I, bls. 409-410. 
In 1555 het Karel V die bestuur oor die Nederlande aan sy seun Filips II oorgedra. Wat die vader nie kon bewerkstellig nie, het die seun op in nog hardvogtiger wyse probeer verwesenlik. Hoe hy teenoor die Hervorming gestaan het, kan ons uit die volgende voorval leer. In 1559 het 'n veroordeelde aan hom gevra „Hoe kan u toelaat dat hulle my verbrand?" Daarop het Filips II geantwoord „Ek sou self die hout aandra om my seun te verbrand indien hy so sleg was as jy is." 7 )

Dat in hierdie dae selfs Katolieke Nederlanders hulself nie met die optrede van hul koning en sy handlangers kon verenig nie, blyk uit die volgende, veelseggende getuienis van Prins Willem van Oranje. Hierdie Nederlandse vryheidsheld het, toe hy nog die Katolieke geloof aangehang het, in 1564 verklaar:

„De koning dwaalt als hij meent dat Nederland, temidden van landen waar godsdienstvrijheid bestaat, voortdurend de bloedige plakkaten verdragen kan... Hoezeer $\mathrm{ik}$ aan het katholieke geloof gehecht ben, ik kan niet goedkeuren dat vorsten over het geweten van hun onderdanen willen heerschen en hun de vrijheid van geloof en godsdienst ontnemen." s)

Prins Willem van Oranje was nie die enigste vooraanstaande Nederlander wat hierdie gedagte gehuldig het nie. En hoe die stemming onder die Nederlandse Calviniste twee jaar later was, blyk uit die feit dat in 1566 predikers in Vlaandere soms meer as 20,000 mense in die opelug toegespreek het. ${ }^{9}$ ) In Augustus van dieselfde jaar het die volksmassa Roomse kerkgeboue begin plunder. Vanuit Vlaandere het hierdie beweging soos 'n veldbrand dwarsdeur die Nederlande getrek. Op verskillende plekke het die Calviniste hierdie kerke vir hul eie dienste begin gebruik. Vir 'n oomblik was die Spaanse regering radeloos, maar Filips II het gou van die eerste skrik herstel en in 1567 'n militêre ekspedisie onder leiding van sy bekwaamste krygsowerste die hertog van Alva — na die Nederlandse gestuur om die opstandige "ketters" te straf. 'n Nuwe uittog van Calvinistiese Nederlanders het gevolg. Alva het sy skrikbewind in die Nederlande begin, maar in 1568 gryp die Calviniste, ondersteun en aangevoer deur Prins Willem van Oranje, na die wapens. Die Tagtigjarige oorlog (1568-1648) het begin. 'n Handjievol onversaagde Nederlanders wat reeds solank die staatkundige en godsdienstige tirannie van die magtigste ryk van die wêreld (Spanje) ondervind het, het hul stryd vir staatkundige en gods-

6) Sien o.a. A. J. Grant: The Huguenots. Londen 1934.

7) Hierdie voorval het in Spanje (Valladolid) plaasgevind. Daar het die Hervorming ook talryke aanhangers gehad. Sien o.a. M. F. van Lennep: De Hervorming in Spanje in de zestiende eeuw. Haarlem 1901. Bogenoemde voorval op bls. 191.

8) Aangehaal deur P. Geyl, 1e deel, bls. 437. Plakkate=wette. Ons kursiveer.

9) P. Geyl, le deel, bls. 456. 
dienstige vryheid en selfbeskikking begin. Reeds na die aankoms van Alva in die Nederlande het ' $n$ onbekende digter gesing:

Al uwe boos' aanslagen,

Verkeerde mensch van hart,

Die zullen God mishagen,

Want hij ze moede werdt.

En wat gij had gegist.

Gij vinden zult gemist. ${ }^{10}$ )

'n Stryd op lewe en dood het ontbrand en in dié dae van benouenis hoor ons weer die stem van 'n gelowige digter wat, na die aankoms van. Alva, aan sy landgenote verkondig:

Helpt nu uzelf, zoo helpt $u$ God,

Uit der tyrannen band en slot.

Benauwde Nederlanden.

Gij draagt den bast al om uw strot, ${ }^{11}$ )

Rept fluks uw vrome ${ }^{12}$ handen.

O Nederland, gij zijt belaen.

Dood ende leven voor u staan:

Dient den tyran van Spanjen,

Of volgt, om hem te wederstaan. ${ }^{13}$ )

Den Prinse van Oranjen.

En wanneer 'n paar jaar later die nood hoog gestyg het, rig 'n ander digter hom in die volgende woorde tot God:

O Heere, wil u erbarmen

Over ' $t$ zuchten en karmen $\left.{ }^{11}\right)$

Van ons, armen, éénpaar,

Want wij zijn in groot lijden.

O Heer, wil ons bevrijden

Uit deez' benauwdheid zwaar! ${ }^{15}$ )

Soos reeds vermeld is, het 'n groot antal aanhangers van die nuwe gedagtes as martelaars omgekom. Ander het daarin geslaag om, deur 'n stilswye te bewaar, in die Nederlande te bly lewe, woon en werk. 'n Groter aantal Nederlanders het besluit om hul geboorteland te ver -

10) Ons kursiveer. In 1568. By die onthoofding van Egmont en Hoorne.

11) Julle dra die strop reeds om jul nekke m.a.w. staan klaar om opgehang te word.

12) vroom $=$ dapper.

13) wederstaan $=$ beveg.

14) karmen - gekerm, éénpaar - almal.

15) "Van den Tienden Penning," Van hierdie en ander "Geuseliedere" verklaar M. Beversluis "De Geuzenliederen zijn de gezangen der ongetemde en wilde Oranjepiraten tegen de godsdienstdwang van Spanje. $\therefore$ Zij bewegen zich op de schommelende maat der geuzenschepen of het nijdige van de trommelslag. Andere weet nemen de breede wijze aan van cen psalm. In het bijzonder denken wij aan het prachtige ..Wilhelmus".... (In "Vive le geus! een bloemlezing geuzenlie deren." Baarn. s.j. 
laat om, op vreemde grond, God op hul wyse te kan eer. Hoeveei Nederlanders het weggetrek? Dit is onbekend, maar in 1567, die jaar waarin die uittog sy hoogtepunt bereik het, het honderdduisend Nederlanders weggetrek. ${ }^{16}$ ) Die handelstad Amsterdam het in daardie jaar oor te min skepe beskik om die emigrante te vervoer. Het die koms van Alva hierdie trekkers laat besluit om pad te gee dan moét daar altyd onthou word dat die trekbeweging reeds in die twintiger jare van die $16 e$ eeu begin het.

Waarheen het hierdie Nederlanders getrek? Vanselfsprekend na stede of gebiede waar hulle ongehinderd hul geloof kon bely. Vlaandere en Zeeland het ou handelskonneksies met 'n aantal stede in WesEngeland besit. Daar het Nederlandse handelshuise floreer en was die bewoners van Vlaandere ${ }^{15}$ ) en Zeeland welkom tydens die regering van koning Hendrik VIII en koningin Elisabet. Uit die provinsie Holland en die noord-oostelike provinsies van die Nederlande verhuis hulle na Emden in Oos-Friesland, uit ander provinsies lei die kortste pad na die Ryngebied, terwyl uit die suidelike provinsies ook persone na Aken getrek het. Later word die Palts, 'n onafhanklike staatjie in die midde Ryngebied nog 'n vestingsentrum, terwyl ons Genève nie moet vergeet nie.

Terwyl dié Nederlanders wat skuiling in Engeland gaan soek het in 'n land met ' $n$ afwykende taal en kultuur gekom het, was dit met dié wat na Emden. Wesel, Keulen e.a. Duitse grensstede getrek het nie die geval nie. Reeds in die Middeleeue het Nederland die Duitse grensgebied kultureel sterk beïnvloed. Ook in die sestiende eeu was dit nog die geval. Taalkundig was daar ook geen beletsels nie, want selfs in ons eeu vertoon die dialekte of streektale in daardie gebiede geen groot afwykings met die dialekte in die Nederlandse grensgebiede nie. Eers in die $19 e$ en $20 e$ eeu het, nadat Duitsland 'n eenheidstaat geword het, die Duitse grensgebiede hulle na Berlyn begin oriënteer. ${ }^{19}$ )

In hierdie grensgebied kom agtereenvolgens die stad Emden in aanmerking. ${ }^{20}$ ) Dat Emden so 'n groot rol gespeel het moet. behalwe aan dié omstandighede wat ons reeds vroeër genoem het, ook aan die volgende faktore toegeskrywe word. Aan die begin van die $16 \mathrm{e}$ eeu

16) Van Schelven, bls. 33.

18) 'n Beknopte oorsig oor Engels-Vlaamse betrekkings: H. W. Howes "The history of Anglo-Belgian relations." Londen 1943.

19) Sien 0.a. P. Geyl. le deel, bls. 299; F. Dekker: Voortrekkers van Oud-Nederland, verspreide bladsye. In 1935 het J. J. Boer in sy akademiese proefskrif "Ubbo Emmius en Oost-Friesland" getuig "Nog tegenwoordig immers is er ondanks de internationale scheiding een frappante gelijkheid tussen het Groninger Oldambt en het Oostfriese Reiderland.... niet slechts in dialect, maar ook in de aanleg der dorpen. de bouw der boerderijen, de sociale geleding der bevolking, de geestelijke ontwikkeling en het zelfbewustzijn der boeren." (bls. 188) Boer toon op verskeie plekke aan dat die bewoners van Emden dikwels hulp van die StateGeneraal van die Nederlande ingeroep het. Sien ook Gregor Heinrich: Wir Friesen. Berlyn 1934. Lingen was van $1634-1732$ in besit van die Oranje-familie. 
was graaf Edzard I „die Grote" bestuurder van Oos-Friesland. Hy het daarin geslaag om teen buitelandse maghebbers sy gesag te handhaaf. Hy sterf in 1528, word opgevolg deur sy seun Enno II. Na sy dood (1540) neem sy weduwee (Anna van Oldenburg) die bestuur tot 1565 waar.

Deur haar toedoen kom in 1543 die Poolse Hervormer Johannes a Lasco na Emden. ${ }^{21}$ ) In die volgende jaar begin die Nederlandse emigrante hul trek na Oos-Friesland. Behalwe te Emden vestig hulle hulself ook te Norden en Leer, maar Emden bly die middelpunt. Die taak wat a Lasco te Emden gewaag het, was nie benydenswaardig nie. Al die emigrante was teen die Roomse geloof maar soos Van Schelven opmerk wanneer hy die samelewing te Emden omstreeks 1567 skets „Een wonderlijk gezelschap was het dat zich toen te Emden ophield. Een ware staalkaart van standen en denkbeelden," ${ }^{22}$ ) En in hierdie verskeidenheid moes a Lasco orde en eenheid skep. Allereers het hy, met die oog op handhawing van die kerklike tug 'n viertal persone aangestel om toesig te hou oor die lewenswandel van die gemeentelede. Hulle was verplig om die lede op hul pligte te wys, te vermaan en indien dit nie sou baat nie het hulle die reg besit om daardie weerspanniges en ongehoorsames in die kerklike ban te doen. So het die eerste kerkraad van Emden sy verskyning gemaak.

'n Tweede stáp van a Lasco was om hom op hoogte te stel met toestande in die ander gemeentes in Oos-Friesland. Een van die uitvloeisels daarvan was dat hy 'n vereniging van predikante van die verskillende gemeentes gestig het. Een keer per week het die leraars bymekaar gekom, oor gemeente-aangeleenthede en -moeilikhede gepraat en alles gedoen om die suiwerheid van die leer te handhaaf, terwyl persone wat hulle vir die predikamp beskikbaar gestel het deur die vergadering o.a. ondervra is, waarna deur stemming oor hul toelating beslis is.

Was bogenoemde maatreëls bedoel om in die nood van die oomblik voorsiening te bring, 'n ander stap van a Lasco was op die toekoms gerig. In 1546 het, nadat a Lasco hulle voorgelig het, die leraars van Emden 'n kategismus opgestel. Hierdie kategismus het uit nie minder as 250 vrae en antwoorde bestaan nie, was bedoel om as leidraad vir godsdiensonderwys in die skole te dien en om op Sondagnamiddagsamekomste van die gemeente gebruik te word.

Tot 1549 kon a Lasco te Emden werk. Dan oefen die Keiser (Karel V) so'n druk op die gravin van Oos-Friesland uit dat sy die bekwame organisator versoek.om die stad te verlaat.

20) Veral die reeds genoemde werke van Van Schelven en Boer (histories) waaruit ons die gegewens geput het.

21) Boer, bls. 6. Oor Johannes a Lasco sien Van Schelven, voetnoot bls. 39 en 40. Van Schelven noem 1540 (bls. 53).

22) Bls. 47. 
In Oktober 1549 vertrek Johannes a Lasco na Engeland en kom in 1550 te Londen aan.

In Londen was a Lasco geen onbekende nie. Voor sy vertrek uit Emden het hy in 1549 'n besoek aan Londen gebring en daar ongetwyfeld heelwat vlugtelinge uit die Nederlande ontmoet. In 1548 was daar ongeveer 5,000 emigrante te Londen. Die meeste van hulle was Franssprekendes (Wale) uit die Suidelike Nederlande. Saam met hulle was die Gentenaar Jan Utenhove. Nog voordat a Lasco in Londen aangekom het, het hierdie landverhuisers oor twee kerkgeboue beskik, ${ }^{23}$ ) een vir die Wale, die ander vir die Franse vlugtelinge. In 1550 is een van hierdie geboue deur ' $n$ ander, 'n verlate kerkgebou van die Augustynse monnike, vervang."') Dit was 'n geskenk van koning Eduard VI (1547-1553). Op die 2le September 1550 is die kerkgebou ingewy, terwyl kort daarna vier ouderlinge ${ }^{25}$ ) en vier diakens benoem is. Kort daarna het hierdie kerkgebou in besit van die Nederlandssprekendes gekom. Sonder om verder op al die werksaamhede van a Lasco te Londen in te gaan kan ons vermeld dat hy reeds kort na sy aankoms aldaar 'n belangrike rol speel. Wanneer die koning die kerkgebou aan die emigrante skenk, geskied dit op naam van Johannes a Lasco en Jan Utenhove. Duidelik word die invloed van a Lasco wanneer ons weet dat hy as Superintendent van die -vlugtelingekerke te Londen benoem is. Aan hom was dus allereers - netsoos in Emden - die inrigting van die Kerk opgedra. Hierdie posisie het hom 'n groot verantwoordelikheid gegee. Onder sy mede-predikante was hy wat Petrus op bevel van Christus onder die apostels was. Hy moes sy broeders in die geloof versterk, vir eendrag in die geledere sorg, die werksaamhede van die leraars reël en daarvoor sorg dat hulle nie "uit de palen haers diensts loopen."

Tog moet ons - uit 'n oogpunt van mag - die Superintendentskap nie oorskat nie, want in die omskrywing van hierdie amp was duidelik neergelê dat, indien die Superintendent 'n kerklike misstap begaan, sy ampsbroeders hom onder kerklike tug kan plaas. ${ }^{26}$ ) Aan die ander kant moet ons die invloed van a Lasco nie onderskat nie. Reeds in Emden het hy getoon watter groot talente hy besit het. In samewerking met ds. Martinus Micronius en ouderling Jan Utenhove is in die jare 1550-'53 omvangrike arbeid deur a Lasco verrig. Allereers noem ons die opstel van ' $n$ geloofsbelydenis wat deur Utenhove in

23) Hierdie en volgende besonderhede is ontleen aan Van Schelven en J. F. Bense ,Anglo Dutch Relations from the earliest times to the death of Wiliam the "Third". Londen-Den Haag 1925. Bls. 92 e.v.

24) Dit was die sgn. .Austin Friars Church" wat van 1560 af deur die Nederl Hervormde gemeente te Londen gebruik is. Tydens hierdie oorlog is hierdie gedenkwaardige gebou tydens 'n bombardement verwoes. Die eerste leraar was ds. Martinus Micronius.

25) Een van die ouderlinge was Jan Utenhove.

26) Van Schelven, bls. 81-82. Van Schelven haal die pragtige woord .Oversiender" aan. 
Nederlands vertaal is. Dan volg 'n kategismus. Hier het a Lasco die Emdense kategismus voorgelê. Utenhove het die Oos-Friese teks in Nederlands vertaal. Dan verskyn 'n kategismus van kleiner omvang en 'n leerboek „Een korte ondersoeckinge des gheloofs." Dat Utenhove nie alleen vertaler was nie, maar ook oor digterlike talente beskik het, word bewys deur sy psalmbundel (1551). Aanvanklik het hierdie bundel 25 psalms bevat, by elke herdruk het die aantal vermeerder. Dan volg daar nog geskrifte in verband met kerkinrigting en liturgie

In 1553 is koning Eduard VI oorlede en opgevolg deur koningin Maria (1553 1558). Sy het die Roomse Kerk in eer herstel, brandstapel en skavot het met hul bloedige werk begin. 'n Deel van die Nederlandse gemeente het besluit om te vertrek om weer die vryheid te gaan soek. Onder hulle was a Lasco, ds. Micronius en Jan Utenhove. Van Schelven ${ }^{2 i}$ ) skets die vertrek van die twee Deense skepe wat die gelowiges na Denemarke sou vervoer in die volgende, gevoelvolle woorde:

.,Met ongeveer 175 personen aan boord begonnen de beide scheepjes de Theems af te zakken naar zee; langs den oever begeleid door de vrienden die achter zouden blijven. Zoo ging het tot aan Gravesend toe, aan de kust, waar het laatste afscheid moest genomen. Een oogenblik van aangrijpenden ernst! Zou men elkaar ooit weerzien? Wat zou er worden van die reizigers, die den winter ingingen onder zulke ongunstige omstandigheden; wat van hen die achter bleven onder de regeering eener vorstin, die het bloed harer onderdanen zocht? Het was geen wonder dat - toen de schepen wegvoeren naar volle zee - uit den kring dier achterblijvenden psalmgezang weerklonk; geen wonder dat men daar ter plaatse God zocht in het gebed en niet naar huis wilde keeren voor men - het was immers Zondag - ten behoeve der armen aalmoezen had bijeengebracht en elkander wit het heilig Woord vertroost."

Hoe was a Lasco en Utenhove op daardie oomblik te moede? Utenhove, die ouderling wat eendag geskrywe het dat hy nie dink nie .,dat onse Nederlantsche natie voor desen tijt oyt Ghemeynte ghehadt heeft, daerin dwoort Gods so louterlick ghepredict is gheweest, de sacramenten so oprechtelik uutgherecht ende de Christeliche straefve so neerstelick ende ghetrouwlick gheoeffent sijn gheweest" as in die Hervormde gemeente te Londen?

Op die koning van Denemarke, 'n voorstander van die Hervorming, was die hoop van die swerwers gevestig. Hoe bitter was hul teleurstelling nadat hulle na aankoms in Denemarke moes verneem dat hulle onmiddellik die land moes verlaat. Die Deense koning was deur sy Lutheraanse raadgewers bang gemaak en in die waan gebring

27) Bls. 106. Ons kursiveer. Die skepe „Die Moor” en „Die Klein Kraai” het op die 17 e September 1553 uit Londen vertrek. 
dat die vlugtelinge die orde en rus in Denemarke sou versteur. In die bitter winterkoue trek die vlugtelinge in groepies weg. In Duitsland word hulle van stad na stad gestuur. Waarheen? Na Emden. Teen die einde en aan die begin van 1554 kom hulle groepsgewys in ,,de herbergh van Gods kercke" aan. Was dit 'n wonder dat hulle, as 'n bewys van dankbaarheid, " $n$ groot gedenksteen bokant een van die ingange van die kerk te Emden geplaas het. Op hierdie steen staan 'n skip, die simbool van die Kerk, en rondom hierdie afbeelding die. volgende woorde:

Gods kerk vervolgt, verdreven, Heft God hyr Trost gegeven. ${ }^{28}$ )

In Emden, wat 'n paar jaar gelede a Lasco moes sien vertrek, is die vlugtelinge met blydskap ontvang. Ongehinderd kon a Lasco weer as Superintendent optree. Dit blyk dat daar ook 'n aantal Engelse en Wale in Emden was. Van nouaf het Emden 'n belangrike rol begin speel. Allereers as 'n middelpunt van die drukpers, tweedens as Moederkerk, derdens as ' $n$ opleidingsentrum en tenslotte deurdat in 1571 te Emden 'n sinode gehou is. ${ }^{29}$ ) Deur tal van Bybeluitgawes, deur psalms van Utenhove en ander kerklike geskrifte het Emden baie daartoe bygedra om die Hervormdes, waar ook al, van leesstof en voorligtende, stigtelike geskrifte te voorsien. Vanuit die Nederlande, wat in sy vryheidsoorlog gewikkel was, het roepstemme opgegaan na Emden om dienaars van die Woord te stuur, om adviese te gee en om mer raad en daad die geloofsbroeders in die Nederlande by te staan. Met betrekking tot hulp en ondersteuning was die feit dat in Emden leraars opgelei is, van -onskatbare waarde. Tenslotte die sinode wat in 1571 te Emden gehou is. ${ }^{30}$ ) Daar is die grondslae vir die inrigting en leidrade vir die toekomstige Nederlands Hervormde Kerk gelê. Ons skrywe: toekomstig. want in 1571 was die Tagtigjarige oorlog nog maar in sy beginstadium. Die vooruitsigte vir die Nederlanders was droewig, maar in 1572 het die provinsies Holland en Zeeland gedeeltelik vrygekom. Hoe hoog hierdie vryheidshelde hul Kerk geskat het, word duidelik wanneer ons daaraan dink dat die eerste sinode op Nederlandse grond reeds in 1574 te Dordrecht gehou is. In 1581 het die sinode van Middelburg gevolg. Omstreeks 1576 was NoordNederland (m.a.w. die teenswoordige Nederland ten noorde van die groot riviere) reeds sover van die Spanjaarde gesuiwer dat die meeste

28) Van Schelven, bls. 112. , Gods Kerk vervolgd, verdreven, Heeft God hier troost gegeven." $K$. ter Laan vermeld onder die naam Emden in sy "Woordenboek van de Vaderlandsche Geschiedenis." (Den Haag-Batavia 1939) „Als een moeder in haar schoot, Borg zij ballingen in nood." Bokant een van die stadspoorte van Emden staan ".Heer, bewaar de Herbarg diner Gemeine." (Here, bewaar die herberg van is gemeente).

29) Van Schelven, bls. 117. 
geloofsballings kon terugkeer. In 1618-'19 volg dan die eerste nasionale sinode van ons Moederkerk in Nederland: die groot, betekenisvolle vergadering te Dordrecht. Eindelik was die doel bereik: vryheid van geloofsoortuiging, vryheid van geloof, vryheid van prediking, 'n nasionale Kerk op eie grond!

Gebrek aan plaasruimte belet ons om die ander gemeentes in die buiteland uitvoerig te behandel. ${ }^{31}$ ) Allereers kom Engeland weer aan die beurt. In 1558 het koningin Maria, wat van 'n deel van haar eie volk die bynaam ,die Bloedige" ontvang het, heengegaan. Onder haar opvolgster, koningin Elisabet (1558-1603) het Engeland, meer as ooit tevore, 'n toevlugsoord vir onderdruktes en vervolgdes geword. Spoedig het dié vlugtelinge wat vroeër van Londen na Emden vertrek het 'n paar verkenners na Engeland gestuur.

In 1559 het ds. Petrus Delenus, wat vroeër te Londen diens gedoen het, saam met Jan Utenhove na Engeland vertrek. Koningin Elisabet het die kerkgebou, wat tydens haar voorganger as 'n vlootpakhuis gebruik was, aan die Nederlandse gemeente teruggegee. Twee jaar later tel die gemeente ongeveer vyf tot seshonderd persone, ${ }^{32}$ ) in 1562 word die getal op 1,000 geskat, terwyl dit in 1568 en 1569 tot byna twee duisend styg. In 1581 staan nog ongeveer 1,300 persone geboek, 'n bewys dat heelwat vlugtelinge reeds weer na hul vaderland teruggekeer het.

Behalwe dat die Nederlandse gemeente te Londen weer nuwe lewe ingeblaas is, het in dieselfde tyd 'n aantal nuwe Nederlandse gemeentes in Engeland ontstaan. Allereers dié van Sandwich (1561) waar 'n vierhonderd mans, vrouens en kinders hul gaan vestig het. Die volgende gemeente is dié van Colchester (1563 of '65). In Norwich was aan die begin van 1568 reeds ruim elfhonderd Vlaamssprekendes gevestig. Dan volg nog die gemeentes Maidstone, Yarmouth, Stamford, Ipswich, Thetford, Lynn, Dover, en Coventry. In 1642 verneem ons nog van Nederlandse gemeentes te Londen, Norwich, Canterbury. Colchester, Sandwich, Yarmouth, Southhampton, Maidstone, Canvey Isle, Isle of Axholme en Hatfield Chase. ${ }^{33}$ ) In hoever ons hier met afstammelinge van die $16 \mathrm{e}$ eeuse emigrante te doen het, is onbekend maar met sommiges van hulle het dit ongetwyfeld netso gegaan as met 'n onbekende Nederlandse briefskrywer uit Norwich wat geskryf het „Vriesland is veel ongeriever dan Noordwijk (Norwich)... ik verdien zooveel dat ik met een gezin van drie kinderen er gemakkelijk van rondkomen kan." ${ }^{31}$ )

30) Voorafgegaan deur die konvent van $*$ Wesel in 1568 . Sien J. Reitsma: "Geschiedenis van de Hervorming en de Hervormde Kerk der Nederlanden," Utrecht 1933. Bls. 165. Voorlopige reëlings getref.

31) Ons verwys die belangstellende leser weer na Van Schelven.

32) Van Schelven, bls. 139. Gee 'n aantal getalle vir verskilende jare. Sien ook Bense, bls. 101 e.v. wat meer besonderhede verskaf. 
In die Ryngebied noem ons die volgende vlugtelinge-gemeentes: Keulen (1544), Wesel (1544), Aken (1544), Goch ( $\pm 1566-1576)$, Emmerik (ña 1560), Frankfort (1555) en Frankenthal (1562). Hierdie laaste gemeente was in die Palts, 'n selfstandige staat onder keurvors Frederik III.

Hiermee kan ons hierdie skets afsluit. Op volledigheid maak dit geensins aanspraak. Die bedoeling was slegs om belangstelling op te wek en aandag te laat val op 'n deel van die geskiedenis van ons Moederkerk en hoe vroeër geslagte alles opgeoffer het om die ontstaan, groei en bloei van ons Moederkerk in die Nederlande en gevolglik ook van ons Kerk in Suid-Afrika moontlik te maak. Vir hulle het die woorde wat ons in Openbaring 3:11 opgeteken vind: „Houd, dat gij hebt, opdat niemand u uwe kroon ontneme" in die volste betekenis en omvang gegeld. Hulle het hierdie gedagte uitgelewe, op ons rus die plig om die kosbare erfenis te handhaaf en op die fondamente, wat daardie soekers na lig en waarheid gele het, voort te bou.

J. Ploeger. 